\title{
TAXONOMIC AND ECOLOGICAL NOTES ON SIMULIUM (GOMPHOSTILBIA) PALAUENSE (DIPTERA: SIMULIIDAE) FROM PALAU, MICRONESIA, WITH REDESCRIPTIONS OF ADULTS AND DESCRIPTIONS OF THE PUPA AND MATURE LARVA
}

\author{
Hiroyuki TAKaOKA ${ }^{1}$ And Douglas A. CRAiG ${ }^{2}$ \\ Received March 23, 1999/Accepted April 27, 1999
}

\begin{abstract}
Redescriptions for the female and male, and descriptions for the pupa and mature larva, of Simulium (Gomphostilbia) palauense Stone are given based on reared adults and immature stages recently collected from Palau, Micronesia. S. palauense has several remarkable pupal and larval characters, which have not (or very rarely) been found in any other species of the subgenus Gomphostilbia, such as, in the pupa, the reduced number (i.e., four) of the gill filaments and the absence of spine-combs on the abdomen; in the larva, the presence of serrations on the lateral margins of the hypostomium, supernumerary mandibular serrations, and accessory sclerites, and the absence of a postgenal cleft. Ecological notes on immature stages are also given.
\end{abstract}

Key words: black fly, Simulium, Simuliidae, Palau, Micronesia

Stone (1964) described three species of Simuliidae from Micronesia. He described Simulium (Gomphostilbia) palauense (then, under the subgenus Eusimulium) from five female and 12 male adult specimens from Palau. This species was transferred to the subgenus Inseliellum by Crosskey (1989), but has been recently assigned in the subgenus Gomphostilbia after one of its paratype males preserved in The Natural History Museum, London (BMNH), was examined (Takaoka and Davies, 1995). The other two species were from Guam, and Chuuk (Truk) State, Federated States of Micronesia.

Larvae of $S$. palauense were collected for the first time by P. S. Cranston at Ngardmau Falls, Babeldoab, Palau in 1997. More larvae and pupae, for the first time, were collected from the same locality by us (D.A. Craig and R.E.G. Craig) in 1998 and adults successfully reared from pupae. In this paper we redescribe the adult female and male, describe the pupa and mature larva from these new specimens, and note briefly on several unusual pupal and larval characters found in this species. Ecological notes on immature stages are also given.

Simulium (Gomphostilbia) palauense Stone Simulium (Eusimulium) palauense Stone, 1964: 633. Simulium (Inseliellum) palauense: Crosskey, 1989: 224. Simulium (Gomphostilbia) palauense: Takaoka and Davies, 1995: 161; Crosskey and Howard, 1997: 34.

Female. Body length $1.8 \mathrm{~mm}$. Head. Slightly narrower than thorax. Frons black, shiny, densely covered with whitish recumbent pubescence, interspersed with several brown hairs, except median longitudinal portion narrowly bare; frontal ratio (i.e., greatest width at vertex: narrowest width near antennal base: height) 1.7-1.9:1.0: 1.8-2.4. Frons-head ratio (greatest width of frons: greatest width of head) 1.0:4.0-4.6. Fronto-ocular area (Fig. 1) deep, rounded apically. Clypeus black, shiny, densely covered with whitish recumbent pubescence, interspersed with brown hairs. Antenna composed of $2+9$ segments, brownish black except scape, pedicel and

1 Department of Infectious Disease Control, Oita Medical University, Hasama, Oita 879-5593, Japan

2 Department of Biological Sciences, University of Alberta, Edmonton, T6G 2E9, Canada 
base of 1st flagellar segment yellow. Maxillary palp composed of 5 segments, dark brown to brownish black, proportional lengths of 3rd, 4th and 5th segments 1.0:1.1: 2.3; sensory vesicle (Fig. 2) small, ellipsoidal, ca. $0.25 \times$ as long as 3rd segment. Maxillary lacinia with 8-11 inner teeth and 10-12 outer teeth. Mandible (Fig. 4) with ca. 20 small inner teeth and no outer teeth though outer margin is very weakly erose. Cibarium (Fig. 5) medially forming a thinly sclerotized plate folded forward from posterior margin, and with Y-shaped, heavily sclerotized medial projection. Thorax. Scutum brownish black, shiny, densely covered with brown recumbent pubescence, intermixed laterally and posteriorly with whitish yellow one. Scutellum brownish black, with brown recumbent pubescence and with brown upright hairs near posterior margin. Postscutellum brownish brown, shiny, bare. Pleural membrane bare. Katepisternum dark brown to brownish black, longer than deep, shiny, with many brown hairs. Legs. Brownish black except fore coxa dark yellow, base of mid tibia white of yellowish white, hind trochanter yellow, basal $2 / 5$ or hind tibia white or yellowish white, basal $2 / 3$ of hind basitarsus and basal $1 / 2$ of 2 nd hind basitarsus white; mid and hind tibiae covered with whitish hairs brightly shiny in light on basal $1 / 3$ and basal $3 / 5$ of posterior and outer surface, respectively. Fore basitarsus somewhat dilated, ca. $5.0 \times$ as long as its greatest width. Hind basitarsus (Fig. 6) slender, parallel-sided, ca. $6.6 \times$ as long as wide, and much narrower than hind femur and tibia, of which greatest breadths are ca. $2.3 \times$ and $1.7 \times$ as wide as basitarsus, respectively. Calcipala and pedisulcus (Fig. 6) well developed. All femora and tibiae densely covered with scale-like hairs (Fig. 8) on outer surface. Claws (Fig. 9) each with large basal tooth. Wing. Length $1.5 \mathrm{~mm}$. Costa with spinules and hairs. Subcosta fully haired. Hair tuft on stem vein brown. Basal portion of radial vein fully haired. Basal cell absent. Abdomen. Basal scale brownish black, with a fringe of pale long hairs; segment 2 dark yellow to light brown except narrow portion near posterior margin brownish black, with light brown tergal plate, whitepruinose and shiny when illuminated, other segments brownish black to black, with dark short hairs; terga 6 , 7 and 8 shiny. Genitalia (Figs. 10 and 11). Sternite 8 bare medially, and with 16-18 dark stout hairs on each side. Anterior gonapophysis triangular, thin, membraneous, densely covered with microsetae, with a few short setae; inner margin well sclerotized and darkened. Genital fork of usual inverted-Y form, with arms curved medially with distinct projection directed forward; base of arms broad with narrow notch inbetween. Paraproct somewhat produced ventrally beyond ventral margin of cercus, covered with 17-23 hairs on outer and ventral surface. Cercus semicircular, with dark hairs. Spermatheca ellipsoidal, well sclerotized except small area at tubal juncture and tube unsclerotized, without internal setae.

Male. Body length $1.6 \mathrm{~mm}$. Head. Much wider than thorax. Upper eye consisting of 12 vertical columns and 13 horizontal rows of large facets. Face black, whitepruinose. Clypeus black, shiny, white-pruinose, moderately covered with dark hairs, intermixed with whitish yellow scale-like pubescence laterally except median longitudinal portion somewhat widely bare on lower $3 / 5$ of clypeus. Antenna composed of $2+9$ segments, yellow except apical 5 or 6 flagellar segments grayish brown; 1st flagellar segment somewhat elongate, ca. $1.5 \times$ as long as 2nd flagellar segment. Maxillary palp composed of 5 segments, grayish brown, proportional lengths of 3rd, 4th and 5th segments 1.0:1.2:2.3; sensory vesicle (Fig. 3) small, ellipsoidal, ca. $0.2 \times$ as long as 3rd segment. Thorax. As in female. Legs. Light brown to brownish black except fore coxa dark yellow, base of mid tibia white, hind trochanter yellow, basal $1 / 3$ of hind tibia yellow, basal $2 / 3$ and a little more of hind basitarsus and basal $1 / 2$ of 2 nd hind tarsal segment white; mid and hind tibiae covered with whitish hairs, which are brightly shiny in light on basal $1 / 3$ and basal $1 / 2$ or a little more of posterior and outer surface, respectively. Fore basitarsus somewhat dilated, ca. $5.1 \times$ as long as its greatest width. Hind basitarsus (Fig. 7) slender, parallel-sided, ca. $5.6 \times$ as long as wide, and much narrower than hind femur and tibia, of which greatest breadths are ca. $2.3 \times$ and $1.9 \times$ as wide as basitarsus, respective1y. Calcipala and pedisulcus (Fig. 7) well developed. All femora and tibiae densely covered with scale-like hairs on outer surface. Wing. As in female except length 1.3 $\mathrm{mm}$, and subcosta with a few hairs. Abdomen. Basal scale brownish black, with a fringe of light brown long hairs. Dorsal surface of abdominal segments black, with brown short hairs; segment 2 with a pair of light brown, large, dorsolateral patches, which are silvery shining when illuminated; segments 5, 6 and 7 each with a pair of shiny, large, dorsolateral patches. Genitalia (Figs. 12-15). Coxite large, ca. $1.9 \times$ as long as wide. Style much shorter than coxite, gradually tapered toward apex, with single apical spine. Ventral plate transverse, much shorter than wide, remarkably produced ventrally, densely covered with microsetae on ventral and posterior surface; basal arms directed outward, then forward. Parameres narrow, each with 2 long parameral hooks 
and several shorter ones. Median sclerite broad, nearly parallel-sided, and with apex rounded. Aedeagal membrane uniformly covered with microsetae. Dorsal plate wide, thin, weakly sclerotized, covering aedeagal membrane.

Pupa. Body length ca. $2.0 \mathrm{~mm}$. Head and Thorax. Integument light to dark brown, moderately or somewhat sparsely covered with round tubercles; antennal sheath bare. Head with 1 facial and 3 frontal pairs of long, simple trichomes (Fig. 16). Thorax with 11 simple trichomes on each side (Fig. 17): 3 long mediodorsal trichomes, 2 dorsolateral ones (1 long and 1 medium) situated anteriorly, 1 medium dorsolateral one situated posteriorly, 2 short anterolateral ones just below gill base, and 3 mediolateral ones ( 1 long and 2 short). Gill (Figs. 18 and 19) with 4 simple, slender filaments on each side, arranged in pairs, arising from short basal common stalk; ventral pair of filaments with short stalk, and distinctly longer and thicker than dorsal pair of filaments which are sessile; inner filament in each pair is slightly longer and thicker than outer one; filaments somewhat variable in length by individual pupae, with longest filament (i.e., inner filament of ventral pair) 1.1-1.6 mm, and shortest one (i.e., outer filament of dorsal pair) $0.7-1.2 \mathrm{~mm}$; basal portion of inner filament of ventral pair subequal in thickness to interspiracular trunk; all filaments light to dark brown, gradually tapered toward apex, furnished with annular ridges and furrows, and densely covered with minute tubercles on outer surface. Abdomen. Terga 1, 2 and 9 grayish brown, well sclerotized, other terga also sclerotized (and also dark-colored) to varying extent. Tergum 1 with 1 medium, simple seta on each side; tergum 2 with 1 medium, simple seta and 5 short, simple setae on each side; terga 3 and 4 each with 4 hooked spines directed forward and 2 short, simple setae on each side; tergum 5 with several short simple setae near posterior margin and comb-like groups of very minute spines anterolaterally on each side; terga 6-8 each with 1 short, simple seta near posterior margin and comb-like groups of very minute spines transversely near anterior margin; tergum 9 with a pair of distinct, simple, terminal hooks (Figs. 20 and 21) somewhat bent anterodorsally, and with apex rounded, and comb-like groups of very minute spines transversely near anterior margin; terga 5-9 without spine-combs. Sternum 3 with a few short simple setae on each side; sternum 4 with 1 simple hook and 3 short simple setae (1 of them somewhat longer and stouter) on each side; sternum 5 with a pair of bifid or trifid hooks submedially on each side; sterna 6 and 7 each with a pair of bifid or trifid submedial hook and bifid or simple lateral hook, and 2 short simple setae, on each side; sternum 8 usually darkened to some extent, with 1 short simple seta on each side; sterna 6-8 each with comb-like groups of very minute spines; sternum 9 darkened, bare; segment 9 with 3 grapnel-shaped hooklets laterally on each side (Fig. 22). Cocoon. Simple, wall-pocket-shaped (or slipper-shaped), somewhat roughly woven, with several small open spaces in webs, with anterior margin not thickly woven, and not extending ventrolaterally (though 1 of 12 cocoons examined extends slightly); floor woven on posterior $1 / 2$; individual threads distinct; $2.3-2.5 \mathrm{~mm}$ long $\times 1.0-1.3 \mathrm{~mm}$ wide.

Mature larva. Body length 3.8-4.3 mm. Body color grayish green, often mottled with violet brown markings on posterior abdominal segments, in most of larvae, or yellowish or yellowish brown in some. Cephalic apotome (Photo.1) pale except narrow area along posterior margin somewhat darkened, with distinct positive head spots; ventral and lateral surfaces darkened except eye spot areas. Cervical sclerites (Photo. 1 ), which are absent in earlier instars, rod-like, laterad and not fused to occiput in last instar. Antenna composed of 3 segments and apical sensillum, much longer than stem of labral fan; proportional lengths of 1st, 2nd and 3rd segments 1.0:0.6:1.1. Labral fan with stem slightly flattened, posterobasal corner notched, with $36-$ 40 rays, $0.86 \mathrm{~mm}$ in length, medium brown, width of medial rays $0.012 \mathrm{~mm}$, microtrichia of similar length, pattern of longer microtrichia with 3-4 slightly smaller ones between. Mandible (Fig. 23) with comb-teeth decreasing in size from 1st to 3rd; mandibular serrations composed of 1 large and 1 small teeth; supernumerary serrations present. Hypostomium (Fig. 24 and Photo. 2) with a row of 9 apical teeth, of which median and corner teeth are largest, subequal in length to each other, and 3rd and 7th teeth are smallest; lateral serrations well developed; hypostomal bristles 5 or 6 in row, diverging posteriorly from lateral margin on each side. Postgenal cleft (Photo. 2) absent. Thoracic and abdominal cuticle almost bare except small areas on both sides of anal sclerite covered with pale short setae. Rectal papilla compound, each of 3 lobes with 0-2 (mostly 1) fingerlike secondary lobules ventrally. Anal sclerite (Fig. 25) $\mathrm{X}$-shaped, posterior arms longer than anterior ones; accessory sclerites present, extending ventrally and continuous to each other (in earlier stages, accessory sclerites are present likewise but they are usually discontinuous at the ventral midline). Ventral papillae present ventrolaterally. Posterior circlet of hooks with 
ca. 104 rows of up to 13 hooks per row.

SPECIMENS EXAMINED. Immature larvae, collected at Ngardmau Falls, NW Babeldoab Is., Palau, 14.VII.
1997, P.S. Cranston. Reared adults (7 females and 1 male), all associated with their pupal exuviae and cocoons, 25 pupae, and 10 mature larvae, many other mature and immature larvae collected from first rapid

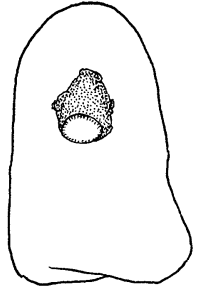

2

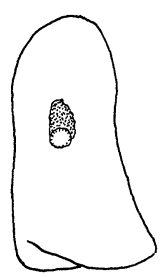

3

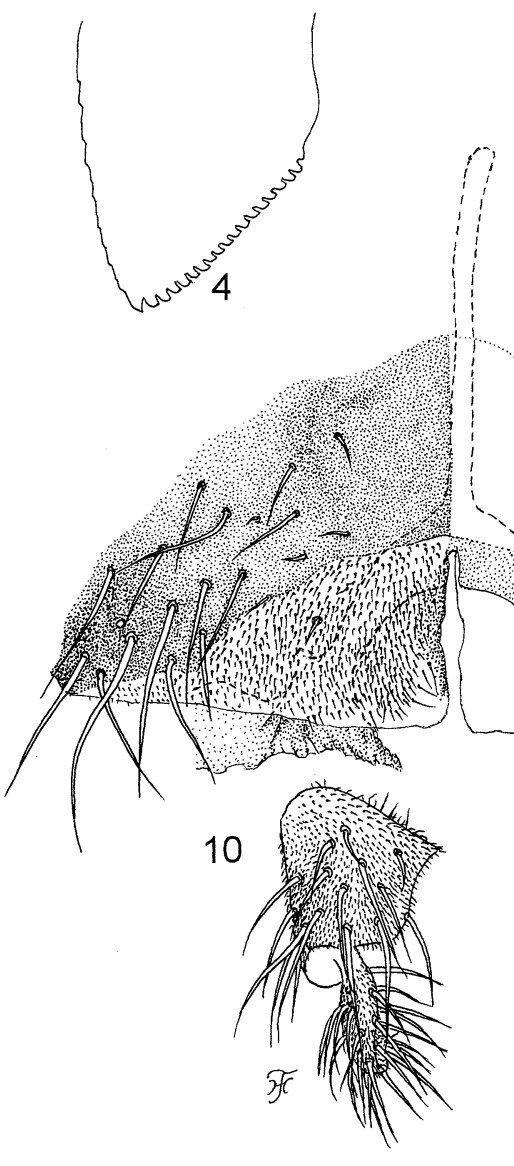

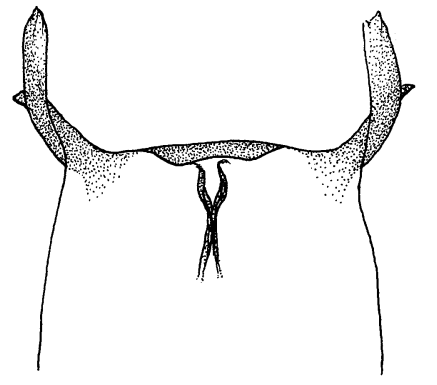

5

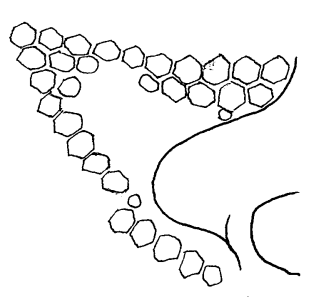

1

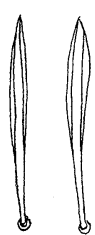

8
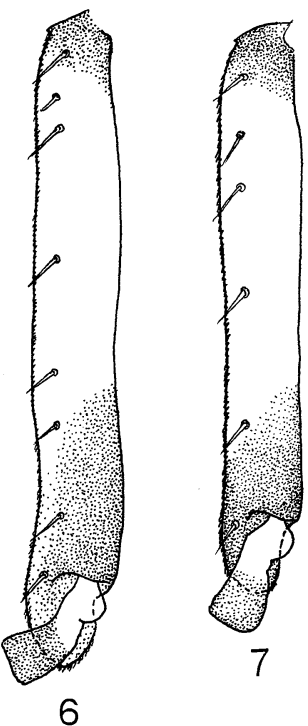
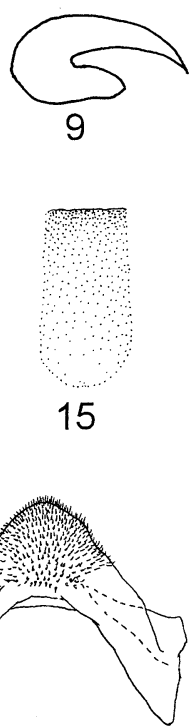

13

Figs. 1-15 Characters of the female and male of Simulium (Gomphostilbia) palauense. 1, fronto-ocular area of female; 2 and 3, 3rd segments of maxillary palp showing sensory vesicle (2, female and 3 , male); 4, apex of female mandible; 5, cibarium of female; 6 and 7, basitarsi and 2nd tarsal segments of hind legs (6, female and 7, male); 8 , scale-like setae of femora and tibiae of female; 9 , female claw; 10 , female genitalia in situ (ventral view) showing 8th sternite, anterior gonapophyses, genital fork, paraproct and cercus; 11, paraproct and cercus (lateral view); 12, male genitalia in situ (ventral view) showing left coxite and style, and ventral plate; 13, ventral plate (end view); 14, paramere (dorsal view); 15, median sclerite. 
on the main tributary (Photo. 3) of the Diongradid River, near Ngardmau Falls, NW Babeldoab Is., Palau, 4.XII.1998, D.A. Craig and R.E.G. Craig.

DEPOSITION OF MATERIAL. 4 reared adults (3 females, 1 male), together with their pupal exuviae and cocoons, 5 pupae, 5 mature larvae (Bernice P. Bishop Museum, Honolulu), 2 female reared adults, together with their pupal exuviae and cocoons, and 5 pupae, 5 mature larvae (H. Takaoka, Oita Med. Univ.), 2 female reard adults, together with their pupal exuviae and cocoons, 5 pupae, and many other mature and immature larvae (D.A. Craig, Univ. Alberta). All these specimens are preserved in $80 \%$ ethanol.

ECOLOGICAL NOTES. The locality, known generally as Ngardmau Falls is a major tourist attraction in Palau. Since road travel is impossible if it has been raining, the falls are best reached by boat, from Koror, up the westernside of Babeldoab, a one-hour voyage to

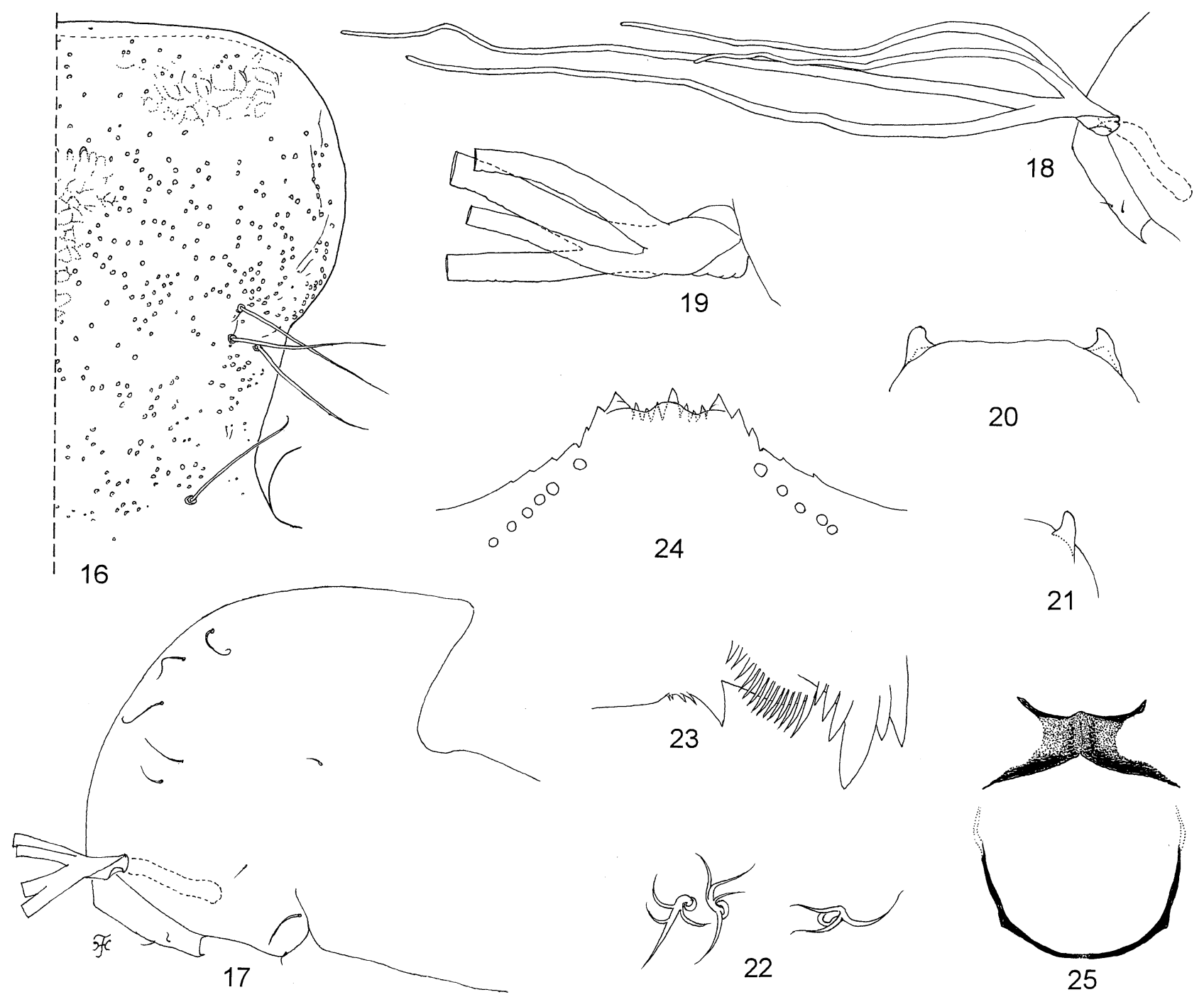

Figs. 16-25 Characters of the pupa and mature larva of Simulium (Gomphostilbia) palauense. 16-22, pupa; 23-25, mature larva. 16, frons and part of face (left half only); 17, thoracic integument (lateral view) showing arrangement of 11 trichomes; 18, gill filaments (lateral view); 19, basal portion of gill filaments (dorsal view); 20 and 21, terminal hooks (20, end view and 21, lateral view); 22, grapnelshaped hooklets; 23, apex of mandible; 24, anterior half of hypostomium; 25, anal sclerite with a well developed accessory sclerite. 


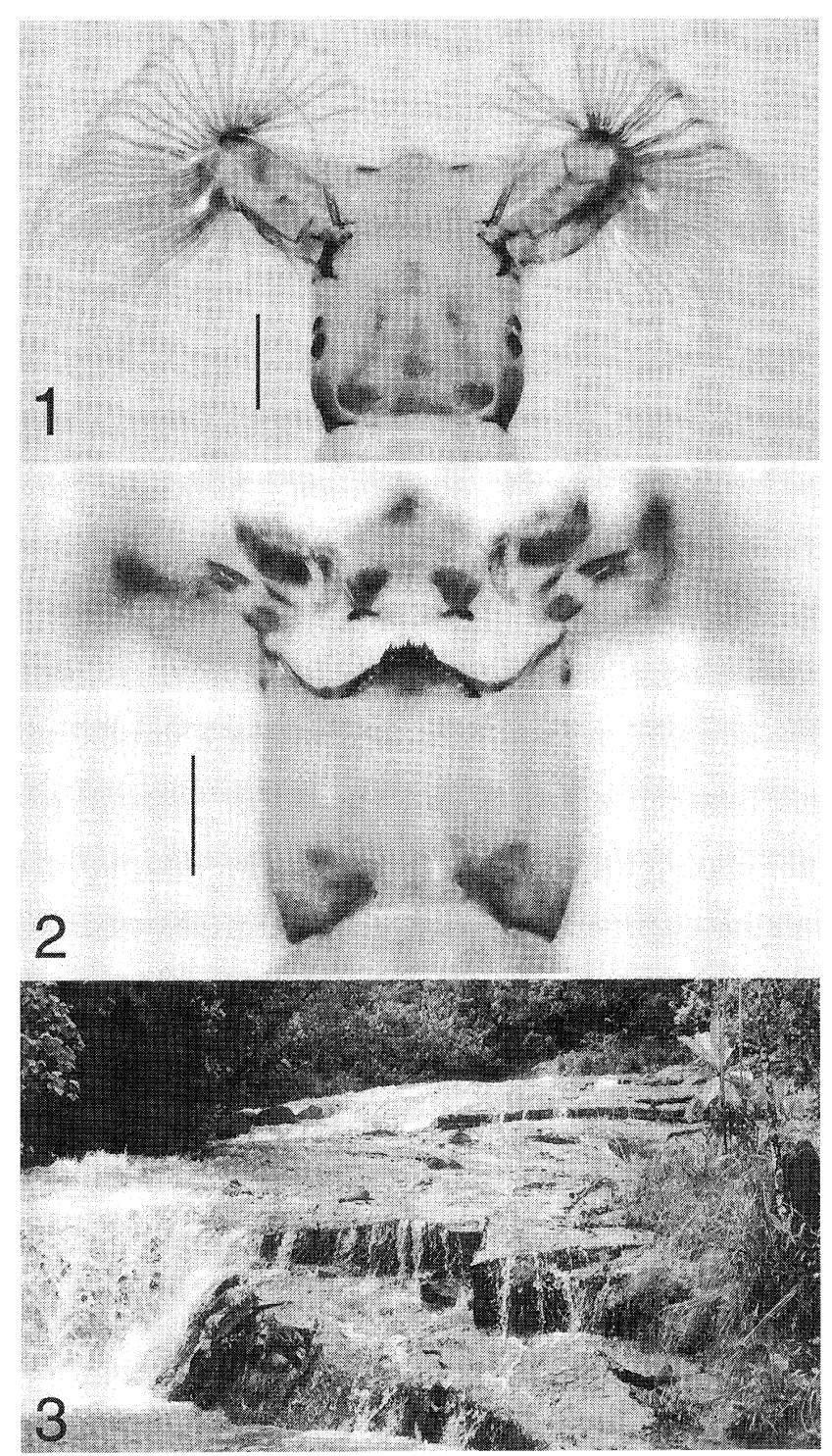

Photos. 1-3 1 and 2, head capsule of mature larva of Simulium (Gomphostilbia) palauense (1, dorsal view; 2, ventral view; scale bars $=0.2 \mathrm{~mm}) ; 3$, habitat of $S$. $(G$.) palauense larvae: first rapid, main tributary of the Diongradid River, near Ngardmau Falls, NW Babeldoab Is., Palau.

the Ucherael jetty and then by vehicle past Ngetbong Village. A one-hour walk up the Diongradid River passes the Medallaiechad waterfall, which is the main attraction, and shortly thereafter reaches a major rapid at N7 $7^{\circ} 35^{\prime} 267^{\prime \prime}$; E134 $35^{\prime} 304^{\prime \prime}$. The river here is at $10 \mathrm{~m}$ altitude, $8 \mathrm{~m}$ wide, between $1-7 \mathrm{~cm}$ depth and flowing extremely rapidly, with velocities of $125-300 \mathrm{~cm} / \mathrm{s}$. Air temperature was $31.5^{\circ} \mathrm{C}$ and water temperature $27.0^{\circ} \mathrm{C}$ under overcast conditions. Since the substrate was black basalt, water temperatures are likely to be much higher in full sunshine. Conductivity was $40 \mu \mathrm{S}$ and pH 8.0.
Particulate material in the water was $1.30-1.90 \mathrm{mg} / l$.

Larvae and pupae were found in large numbers on the rock in full flow and also on leaves that were trapped in shallow water which flows over them. The leaves appeared to be the preferred habitat. Larvae of S. palauense do not twist their bodies longitudinally, similar to larvae of the madicolous-flow inhabiting Tahitian S. (Inseliellum) cataractarum (Craig, 1997). From the same rapid, collected was a single immature larva of the other simuliid species. This second species lacks a postgenal cleft like $S$. palauense, but has welldeveloped ventral papillae placed ventrally, no supernumerary serration on the mandible, and no accessory sclerite around the posterior circlet of hooks. No other invertebrates were taken except a few Chironomidae larvae and aquatic pyralid lepidopteran larvae.

Since this is the only locality sampled for immature stages of simuliids in Palau, and S. palauense larvae appear specialized for fast flow, it is possible that smaller streams, yet unsampled, will have the second or other species.

REMARKS. Female and male adults reared from pupae collected by un (D.A.C. and R.E.G.C.) are conspecific to those of S. palauense described by Stone (1964), according to the comparison of the genitalia, and the shape and coloring of the body and legs. This result confirms that the association of both sexes of adults of $S$. palauense made by Stone was correct. The morphological characters of the present adult specimens agree with the original descriptions and illustrations given by Stone (1964) except a few characters. In the original, terga 8 and 9 of the female abdomen were stated to be shiny, but in fact terga 6, 7 and 8 (and also 9) are all shiny; in addition, gray-pruinose areas were mentioned to be present at least on sides of tergum 2 of the male abdomen, but these are found on terga 2, 5, 6 and 7; the female calcipala is large but not reaching the apex of the second tarsal segment, though noted so in the original description.

It is noteworthy that $S$. palauense has several remarkable pupal and larval characters which are not (or very rarely) possessed by any other species of the subgenus Gomphostilbia. In the pupa, the absence of spine-combs on the abdomen has not been recorded previously in this subgenus, though this is one of the key characters of the subgenus Wallacellum (Takaoka, 1983); the reduced number (i.e., four) of the gill filaments has been known only in a few species of the ceylonicum-group collected from Sulawesi and Flores, Indonesia (Takaoka, unpublished data) and in one 
species from the Solomon and Bougainville Islands (Takaoka, 1994, 1995). In the larva, three characters, i.e., the absence of a postgenal cleft, the presence of serrations on the lateral margins of hypostomium, and the presence of supernumerary mandibular serrations, have not been found; in addition, this species has accessory sclerites on the last abdominal segment, a character being reported only in a few Gomphostilbia species collected from Papua New Guinea (Smart and Clifford, 1965) and Irian Jaya (Takaoka, unpublished data).

Although having such unusual characters, $S$. palauense belongs in the subgenus Gomphostilbia by having the following combinations of characters: adult thorax with the bare pleural membrane and haired katepisternum, wing with the basal portion of radial vein fully haired, male genitalia with a ventral plate hairy on its ventral and posterior surface, and with several parameral hooks, pupal head with three pairs of frontal trichomes, pupal abdomen with grapnel-shaped hooklets on the sides of the last segment, and larval abdomen with ventral papillae. This species is further assigned in the batoense-group, defined by Takaoka and Davies (1996), by having the antenna of both adult sexes 11-segmented, the female tarsal claw with a large basal tooth, and the male hind basitarsus parallel-sided, though the pupal gill filaments of this species are four in place of eight.

Larvae of $S$. palauense show considerable morphological convergence with the madicolous-flow inhabiting larvae of $S$. cataractarum of Tahiti (Craig, 1997). While there is not the same reduction in number of labral fan rays, the fan stem is similarly slightly flattened and possesses a posterobasal notch. Craig and Currie (1999) suggest that this fan-stem shape is used to manipulate madicolous flow into the fans. The postgenal cleft in $S$. cataractarum while present, is reduced. Body shape is also similar, in that both have amphorashaped posterior abdomens, expanded rapidly at the 5th abdominal segment and smoothly decreased posteriorly; probably an adaptation for fast flow.

Both species possess a sclerite that is continuous around the circlet of hooks. In $S$. cataractarum, this appears to be an extension of the accessory sclerite, which remains very obvious, and is connected dorsally with the anal sclerite proper. However, the extension is often discontinuous at the ventral midline. In S. palauen$s e$ this sclerite is constructed differently and is not connected to the anal sclerite proper, but is continued strongly completely around the circlet. The only evidence of the accessory sclerite, as known in other subgenera, is a paler dorsolateral area (Fig. 25).

\section{ACKNOWLEDGEMENT}

This study was supported in part by the Grant-inAid of Ministry of Education, Science and Culture, Japan (no. 11670246) to H.T. Financial support for D.A. C. was from the Natural Sciences and Engineering Council of Canada, grant \# OG5753.

\section{REFERENCES}

1) Craig, D.A. (1997): A taxonomic revision of the black fly subgenus Inseliellum (Diptera: Simuliidae). Can. J. Zool., 75, 855-904

2 ) Craig, D.A. and Currie, D.C. (1999): Phylogeny of the Central-Western Pacific subgenus Inseliellum (Diptera: Simuliidae). Can. J. Zool. (in press)

3 ) Crosskey, R.W. (1989): Family Simuliidae. In: N.L. Evenhuis ed. "Catalog of the Diptera of the Australasian and Oceanian Regions". Bishop Mus. Spec. Pub. 86, 1155p. Bishop Mus. Press, Honolulu.

4) Smart, J. and Clifford, E.A. (1965): Simuliidae (Diptera) of the territory of Papua and New Guinea. Pac. Insects, 7, 505-619

5 ) Stone, A. (1964): Diptera: Simuliidae. Insects of Micronesia, 12, 629-635

6 ) Takaoka, H. (1994): A new blackfly species of Simulium (Gomphostilbia) from Solomon Islands, South Pacific (Diptera: Simuliidae). Jpn. J. Trop. Med. Hyg., $22,103-108$

7 ) Takaoka, H. (1995): The Simuliidae (Diptera) from the Bougainville Island, Papua New Guinea. Jpn. J. Trop. Med. Hyg., 23, 253-266

8 ) Takaoka, H. and Davies, D.M. (1995): The black flies (Diptera: Simuliidae) of West Malaysia. Kyushu University Press, Fukuoka, viii $+175 p$. 